International Journal of

Food Microbiology 30 (1996) 87-99

\title{
Prevalence of shigellosis in the U.S.: consistency with dose-response information
}

\author{
Christopher S. Crockett ${ }^{\mathrm{a}}$, C.N. Haas ${ }^{\mathrm{b}, *}$, Aamir Fazil ${ }^{\mathrm{b}}$, J.B. Rose ${ }^{\mathrm{c}}$, \\ C.P. Gerba ${ }^{\mathrm{d}}$

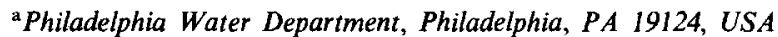 \\ ${ }^{b}$ Drexel University, Environmental Studies Institute, Philadelphia, PA 19104, USA \\ ${ }^{\mathrm{c}}$ Dept. Of Marine Sciences, University of South Florida, St. Petersburg, FL, USA \\ ${ }^{\mathrm{d} D e p t .}$ of Water and Soil Sciences, University of Arizona, Tucson, AZ, USA
}

\begin{abstract}
Every year there are estimated 300000 cases of Shigella in the United States (Bennett et al., 1987, Am. J. Prev. Med. 3, 102-114). A beta-poisson model was fit to human dose-response information on pathogenic Shigella using the Maximum Likelihood Estimation technique (Haas, 1983, Am. J. Epidemiol. 118, 573-582). Pooled and separate dala sels for the Shigella species were fit to the beta-Poisson model and $95 \%$ confidence limits and regions were calculated. Shigella dysentariae and Shigella flexneri confidence regions and limits overlapped with each other and with the pooled data set, suggesting that this model can describe Shigella in general. The pooled Shigella model as well as the upper and lower confidence limits of the three data sets showed average exposures based on the estimated U.S. caseload of pathogenic Shigella of 0.01 to 0.014 organisms (confidence limits 0.001 0.05 ) for a 7-day per annum period of exposure and ranges from 0.07 to 0.1 organisms (confidence limits $0.006-0.4$ ). for a 1 -day per annum period of exposure. The plausibility of the pooled dose-response model was then evaluated by comparison with two known cruise ship outbreaks. The pooled model estimated that the two outbreaks studied could have been due to ingestion of 344 (confidence limits 72-915) Shigella cells per meal and 10.5-12 (confidence limits 1-44) Shigella cells per glass of water by passengers.
\end{abstract}

Keywords: Shigella: Dose-response; Infectious dose; Shigellosis; Risk assessment

\footnotetext{
* Fnvironmental Studies Institute, Bldg. 29-W, Drexel University, Philadelphia, PA 19104, USA. Tel + 1215 8952283; fax: + 1215 8952267; e-mail: haascn@post.drexel.edu
} 


\section{Introduction}

Dating as far back as 1933 there have been documented cases of deaths caused by shigellosis in the United States (Ewald, 1991). Dupont and Hornick, asserted that ingestion of only 10-100 Shigella cells can lead to infection. Since this dosage is much lower than the estimated doses of $10^{5}, 10^{8}$, and $10^{8}$ estimated for probable infection by Salmonella, E. coli, and V. cholerae respectively (Dupont and Hornick, 1973), Shigella can easily be transmitted by person to person contact, food, and water to create adequate exposure for infection. In the United States there are an estimated 300000 cases and 600 deaths per year attributed to infection by Shigella, of which approximately $40 \%$ of these cases are due to ingestion of contaminated food or water sources (Bennett et al., 1987).

Using techniques developed in microbial risk assessment by Haas and co-workers (Haas, 1983; Haas et al., 1993; Regli et al., 1991), one can quantitatively analyze human dose-response data to determine acceptable levels of exposure for prevention of excessive risk to the public. From the analysis of the available dose response data available on Shigella flexneri and dysentariae, one can determine if there is a suitable model to develop guidelines for assessment and management of the risks due to different modes of exposure.

\section{Data background}

The data from dose-response studies involving two species and three strains of pathogenic Shigella used in this paper are shown in Table 1. All the studies involve the use of healthy male adults. The doses and number infected in each study are indicated in Table 1 . In all there are 13 possible data points which could be used to fit a model. The Shigella species denoted with a $2 \mathrm{~A} \#$ \# and $2 \mathrm{~A} \#$ are from the same species and strain, but the differences in notation are used for ease of separation of data results and evaluation in this paper between the two studies performed at two different dates.

\section{Data analysis}

The data were analyzed using a dose-response relationship, which describes the probability of infection, shown as $P_{\mathrm{i}}$, as a function of the administered dose. Prior works (Haas, 1983; Haas et al., 1993; Regli et al., 1991), have shown that the exponential and beta-Poisson models often provide a good fit for microbial dose-response data sets for water and foodborne exposures.

If the distribution of microorganisms in the administered dosage is Poisson, if one microorganism is sufficient to initiate infection, and the host-microorganism interactions are considered constant for each microorganism in any host, then the probability of infection $\left(P_{\mathrm{i}}\right)$ that could result from ingestion of a dosage $d$ of the microorganism, is given as 


$$
P_{i}=1-\exp (-d / k)
$$

where $k$ is the number of ingested organisms that, on average, lead to an infection.

The beta-Poisson model however in most cases, provides a statistically significant improvement in fit over the exponential model. This is because, in general, there is microbial variability in infectivity and host variability in susceptibility. This model was described originally by Furumoto and Mickey (Furumoto and Mickey, 1967a,b) and applied to microbial dose-response estimation by Haas (1983). This is given by:

$$
P_{i}=1-\left[1+d\left(2^{(1 / \alpha)}-1\right) / N 50\right]^{-\alpha}
$$

Table 1

\begin{tabular}{|c|c|c|c|c|c|c|}
\hline Infected With & Strain & Dose & Positive & Negative & $\begin{array}{l}\text { Total \# of } \\
\text { Subjects }\end{array}$ & Reference \\
\hline S. dysenteriae & Pan M-131 & 10 & 1 & 9 & 10 & $\begin{array}{l}\text { (Levine et al., } \\
\text { 1973) }\end{array}$ \\
\hline S. dysenteriae & Pan $M-131$ & 200 & 2 & 2 & 4 & $\begin{array}{l}\text { (Levine et al., } \\
\text { 1973) }\end{array}$ \\
\hline S. dysenteriae & Pan M-131 & 2000 & 7 & 3 & 10 & $\begin{array}{l}\text { (Levine et al., } \\
\text { 1973) }\end{array}$ \\
\hline S. dysenteriae & Pan M-131 & 10000 & 5 & 1 & 6 & $\begin{array}{l}\text { (Levine et al., } \\
1973 \text { ) }\end{array}$ \\
\hline $\begin{array}{l}\text { S. flexneri } \\
2 A \# \#\end{array}$ & $2457 \mathrm{~T}$ & 10000 & 1 & 3 & 4 & $\begin{array}{l}\text { (Dupont et al., } \\
\text { 1969) }\end{array}$ \\
\hline $\begin{array}{r}\text { S. fexneri } \\
2 A \# \#\end{array}$ & $2457 \mathrm{~T}$ & 100000 & 3 & 1 & 4 & $\begin{array}{l}\text { (Dupont et al., } \\
\text { 1969) }\end{array}$ \\
\hline $\begin{array}{l}\text { S. flexneri } \\
2 A \# \#\end{array}$ & $2457 \mathrm{~T}$ & $1 E+06$ & 7 & 1 & 8 & $\begin{array}{l}\text { (Dupont et al., } \\
\text { 1969) }\end{array}$ \\
\hline $\begin{array}{l}\text { S. flexneri } \\
2 A \# \#\end{array}$ & $2457 \mathrm{~T}$ & $1 E+07$ & 13 & 6 & 19 & $\begin{array}{l}\text { (Dupont et al., } \\
\text { 1969) }\end{array}$ \\
\hline $\begin{array}{r}\text { S. flexneri } \\
2 A \# \#\end{array}$ & $2457 \mathrm{~T}$ & $1 \mathrm{E}+08$ & 7 & 1 & 8 & $\begin{array}{l}\text { (Dupont et al., } \\
\text { 1969) }\end{array}$ \\
\hline $\begin{array}{l}\text { S. flexneri } \\
2 A \#\end{array}$ & $2457 \mathrm{~T}$ & 180 & 6 & 30 & 36 & $\begin{array}{l}\text { (Dupont et al., } \\
1972 \text { ) }\end{array}$ \\
\hline $\begin{array}{l}\text { S. Alexneri } \\
2 A \#\end{array}$ & $2457 \mathrm{~T}$ & 5000 & 33 & 16 & 49 & $\begin{array}{l}\text { (Dupont ct al. } \\
1972 \text { ) }\end{array}$ \\
\hline $\begin{array}{l}\text { S. flexneri } \\
2 A \#\end{array}$ & $2457 \mathrm{~T}$ & 10000 & 66 & 21 & 87 & $\begin{array}{l}\text { (Dupont et al., } \\
1972 \text { ) }\end{array}$ \\
\hline $\begin{array}{l}\text { S. flexneri } \\
2 A \#\end{array}$ & $2457 \mathrm{~T}$ & 100000 & 15 & 9 & 24 & $\begin{array}{l}\text { (Dupont et al., } \\
\text { 1972) }\end{array}$ \\
\hline
\end{tabular}

Experimental data sets for Shigella

S. flexneri 2A \# \# represents data from Dupont and Hornick's 1969 test.

S. flexneri 2A \#-represents data from Dupont and Hornick's 1972 test.

This notation is used for distinction between data sets.

Positive subjects were defined as having signs of illness or infection such as fever, diarrhea, positive stool isolations, or antibody positive. 
Table 2

Dose response parameters

\begin{tabular}{|c|c|c|c|c|c|c|}
\hline & \multicolumn{6}{|c|}{ Species/strain } \\
\hline & S. $d y s 131$ & $\begin{array}{l}\text { S. flexneri } \\
2 \mathrm{~A} \# \#\end{array}$ & $\begin{array}{l}\text { S. flexneri } \\
2 \mathrm{~A} \# \#\end{array}$ & $\begin{array}{l}\text { S. flexneri } \\
2 \mathrm{~A} \#\end{array}$ & Pooled & Pooled \\
\hline Dose removed & None & None & $1 \mathrm{E}+7$ & None & None & $\begin{array}{l}1 \mathrm{E}+7 \\
2 \mathrm{~A} \# \#\end{array}$ \\
\hline \multicolumn{7}{|c|}{ Exponential model } \\
\hline $\mathrm{k}$ & 2210 & 9080000 & 9520000 & 14908 & 14414 & 14415 \\
\hline $2 \ln \mathrm{L}$ & 13.21 & 73.6 & 73.55 & 168.59 & 551.64 & 299.03 \\
\hline$P_{o}$ & 0.0042 & $7.2 \mathrm{E}-16$ & $7.35 \mathrm{E}-16$ & $2.5 \mathrm{E}-36$ & $2.2 \mathrm{E}-110$ & $1.4 \mathrm{E}-57$ \\
\hline \multicolumn{7}{|c|}{ beta-Poisson model } \\
\hline$\alpha$ & 0.277 & 0.144 & 0.258 & 0.265 & 0.162 & 0.2099 \\
\hline N50 & 238 & 35400 & 29400 & 1482 & 1127 & 1120 \\
\hline $2 \ln \mathrm{L}$ & 0.032 & 3.44 & 1.26 & 8.73 & 24.0 & 16.85 \\
\hline$P_{\mathrm{o}}$ & 0.9844 & 0.3288 & 0.5337 & 0.0127 & 0.0127 & 0.0778 \\
\hline
\end{tabular}

If $P_{\mathrm{o}}>0.05$ the fit is accepted, if $P_{\mathrm{o}}<0.05$ the fit is rejected.

The $2 \ln \mathrm{L}$ value is compared to the chi-squared statistic for number of degrees of freedom equal to the number of data points minus the number of parameters used.

The $2 \ln \mathbf{L}$ value is twice the $\log$-likelihood value determined using the MLE method for each specified data set and model.

where $\alpha$ is a measure of the model's closeness to the Poisson(exponential) model and N50 is the median infective dose or dose required to infect half of the exposed population. As $\alpha$ approaches infinity, the Poisson model is approached.

From the data sets in Table 1, the best fit values of the parameters were found using the maximum likelihood estimation (MLE) procedure (Haas, 1983; Haas et al., 1993; Regli et al., 1991). Each column of Table 2 shows the dose response parameter estimate values for each of the data sets for the two models. Some columns show the dose response parameter estimate values for specific strains where a specific point was removed for an acceptable fit. Also, Table 2 shows the dose response parameter estimate values when the data sets are pooled to determine whether the Shigella species could be characterized by a single dose response function.

Initial examination of the data (Figs. 1 and 2) suggested that the $S$. flexneri $2 A$ \# \# data contained an 'outlier' at the $10^{7}$ dose level. Several additional analyses supported the hypothesis that this dose level might represent an aberrant observation. First, the contribution of this dose level to the lack-of-fit likelihood ratio statistic was the greatest of all the dose levels. Second, when a monotonic test for trend was performed (Lee, 1988), inclusion of all data points resulted in failure to reject the null hypothesis of no trend $(P=0.057)$, while deletion of this dose level resulted in a statistically significant $(P=0.014)$ trend. Based on this analysis, the further quantification of the dose-response information was performed both including all data points, as well as excluding the $10^{7}$ dose from the $S$. flexncri $2 A \#$ \# data. 
When the data sets were pooled together, the combined data sets did not provide a statistically significant fit to the models $(P \geq 0.05)$. However, removal of the $10^{7}$ dose from the $S$. flexneri $2 A$ \# \# data set resulted in a statistically significant fit to the dose-response models $(P \geq 0.05)$. In later statistical comparisons between the pooled and separated models only the results from the separated data sets with the outlier dose removed were used.

In most cases the beta-Poisson model fit the data, while the exponential model did not fit at all, even when certain doses where removed. Table 3 shows the significance in improvement from the exponential to the beta-Poisson model. The test for improvement was done by comparing two times the difference in the log-likelihood values to the chi-squared statistic for one degree of freedom since the number of parameters in the dose-response models increases by one from exponential to beta-Poisson. If the difference was more than the chi-squared statistic ( $P \leq$ 0.05 ), then the beta-Poisson model showed a statistically significant improvement in fit. Table 4 also performs a test for improvement, but this is for improvement in fit by pooling the Shigella data versus the data fitted separately for each Shigella species. In this test the $2 \ln \mathrm{L}$ values for the three separate Shigella species were summed and subtracted from the $2 \mathrm{ln} \mathrm{L}$ value for the pooled Shigella data. Then to

\section{Predicted \& Observed values for S. flexneri 2a\#}

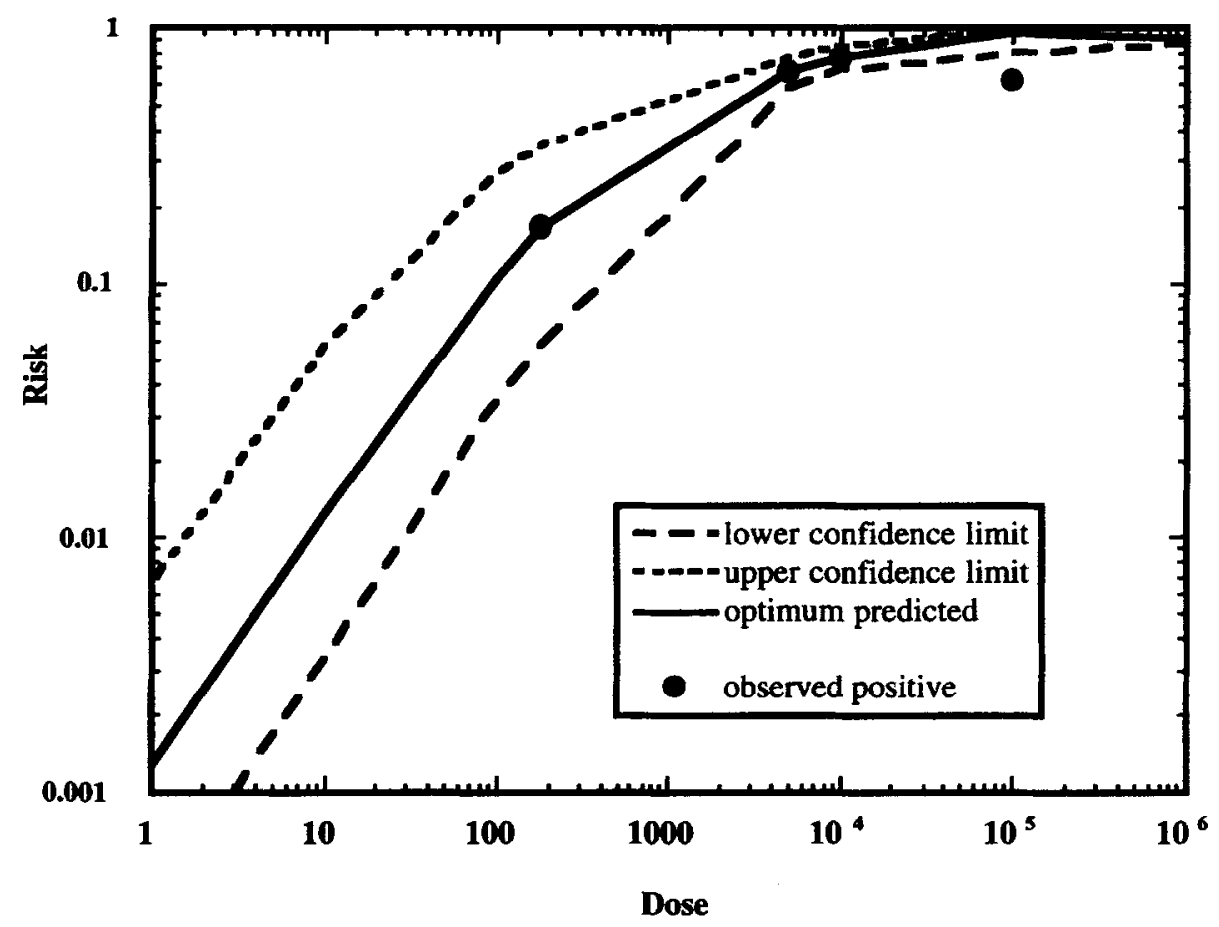

Fig. 1. Comparison of fitted and observed dose-response data for Shigella flexneri $2 \mathrm{~A} \#$. 


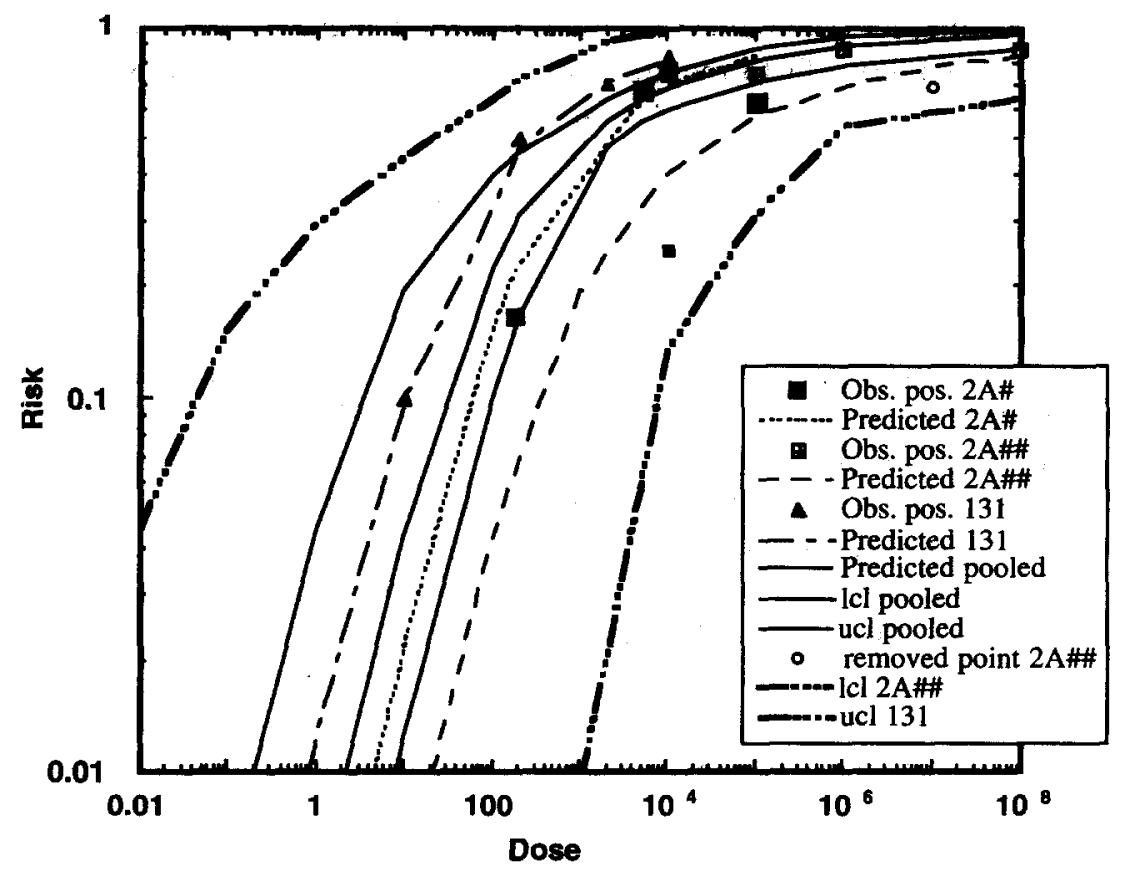

Fig. 2. Overlap of $95 \%$ confidence limits and predicted curves of separate species with all species pooled $95 \%$ confidence limits and curves.

determine whether there was a statistically significant improvement, the delta $2 \ln L$ value was compared to the chi-squared statistic for four degrees of freedom. If the difference was less than the chi-squared statistic $(P \geq 0.05)$ then the pooled Shigella dala fil was statistically indistinguishable from the separate Shigella species fit. The value of $P_{\mathrm{o}}$ was greater than 0.05 , with a value of 0.1452 . Therefore the null hypothesis that the data sets are indistinguishable cannot be rejected.

The 95\% upper and lower likelihood-based confidence limits for the pooled model for Shigella and the individual Shigella species predicted infectivity curves are shown in Fig. 2, from this graph one can see that the pooled Shigella model

Table 3

Improvement in fit with beta-Poisson model versus exponential model

\begin{tabular}{lllllll}
\hline Strain & Pan M-131 & $2 \mathrm{~A} \# \#$ & $2 \mathrm{~A} \# \#$ & $2 \mathrm{~A} \#$ & Pooled & Pooled \\
\hline Dose removed & None & None & $1 \mathrm{E}+7$ & None & None & $1 \mathrm{E}+7$ \\
& & & & & & $2 \mathrm{~A} \# \#$ \\
$\operatorname{Exp} 2 \ln \mathrm{L}$ & 13.21 & 73.67 & 73.6 & 168.6 & 551.64 & 299.03 \\
Beta $2 \ln \mathrm{L}$ & 0.032 & 3.44 & 1.26 & 8.73 & 24 & 16.85 \\
$42 \ln \mathrm{L}$ & 13.178 & 70.16 & 73.55 & 159.86 & 527.64 & 282.18 \\
$P_{\text {o }}$ & 0.003 & $5.5 \mathrm{E}-17$ & $9.8 \mathrm{E}-18$ & $1.2 \mathrm{E}-36$ & $9.2 \mathrm{E}-117$ & $2.5 \mathrm{E}-63$ \\
Improvement & Yes & Yes & Yes & Yes & Yes & Yes \\
\hline
\end{tabular}


Table 4

Test for statistical indifference: pooled and separate data sets

\begin{tabular}{lcl}
\hline Strain & Beta $2 \ln \mathrm{L}$ & No. of parameters \\
\hline Pan M-131 & 0.0315 & 2 \\
$2 \mathrm{~A} \# \#$ & 1.2556 & 2 \\
$2 \mathrm{~A} \#$ & 8.731 & 2 \\
Pooled & 16.8464 & 2 \\
2 In L & 6.8283 & \\
$P_{\mathrm{o}}$ & 0.1452 & 4 d.f.(6 separate $/ 2$ pooled $)$ \\
\hline
\end{tabular}

Chi-square value at 4 d.f. $=9.488(P=0.05)$.

Data sets are statistically the same only if $P_{0}>0.05$.

If $P_{\mathrm{o}}<0.05$ data sets are statistically different than one another.

Outlier removed from $2 \mathrm{~A} \#$ \# data set.

definitely overlaps the other Shigella species predicted infectivity curves except for the $2 \mathrm{~A} \#$ \# strain. However, the $2 \mathrm{~A} \#$ \# strain $95 \%$ upper confidence limit was found to equal one, creating an overlap to some extent between the 2A \# \# and pooled models. These overlaps confirmed the adequacy of the pooled Shigella model to determine a representable predicted infectivity. If the highest 95\% upper confidence limit (in our case Pan M-131) and lowest 95\%

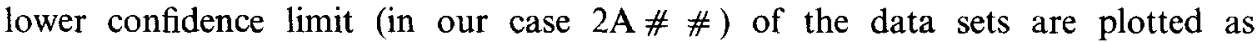
shown in Fig. 2, and the upper confidence limit of $2 \mathrm{~A} \# \#$ is excluded, the pooled Shigella model infectivity curves are contained within these boundaries again confirming the adequacy of the pooled Shigella model to determine a representable predicted infectivity.

If the $95 \%$ confidence regions are determined and plotted for the acceptable models for each data set and the pooled data sets as shown in Fig. 3, some interesting observations can be made. The Shigella pooled model confidence region overlaps all of the other data set confidence regions and encompasses the best fit parameter of the data set for Shigella $2 A$ \#. The considerable overlap in the confidence regions, shows that the fitting technique used is fairly robust to the removal of the outliers from the pooled data set. The pooled Shigella confidence region is fairly small when compared to the other Shigella species confidence regions plotted in Fig. 3 and when ranges of N50 are compared in Table 5. This is expected because an increased number of observations will decrease the estimated variance. The upper confidence limit in the range of alpha does not go past 1.5 and the lower confidence limit goes substantially below an alpha of 1 , indicating that there is a deviation in the data from the exponential model. The uncertainty in the estimation of alpha for the pooled model is about a factor of three and N50 is about a factor of eight. Also, in Fig. 3 one can see

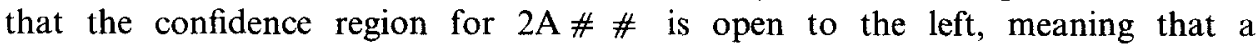
median infective dose could be much less than 10 organisms indicated by Dupont and Hornick (Dupont and Hornick, 1973). 


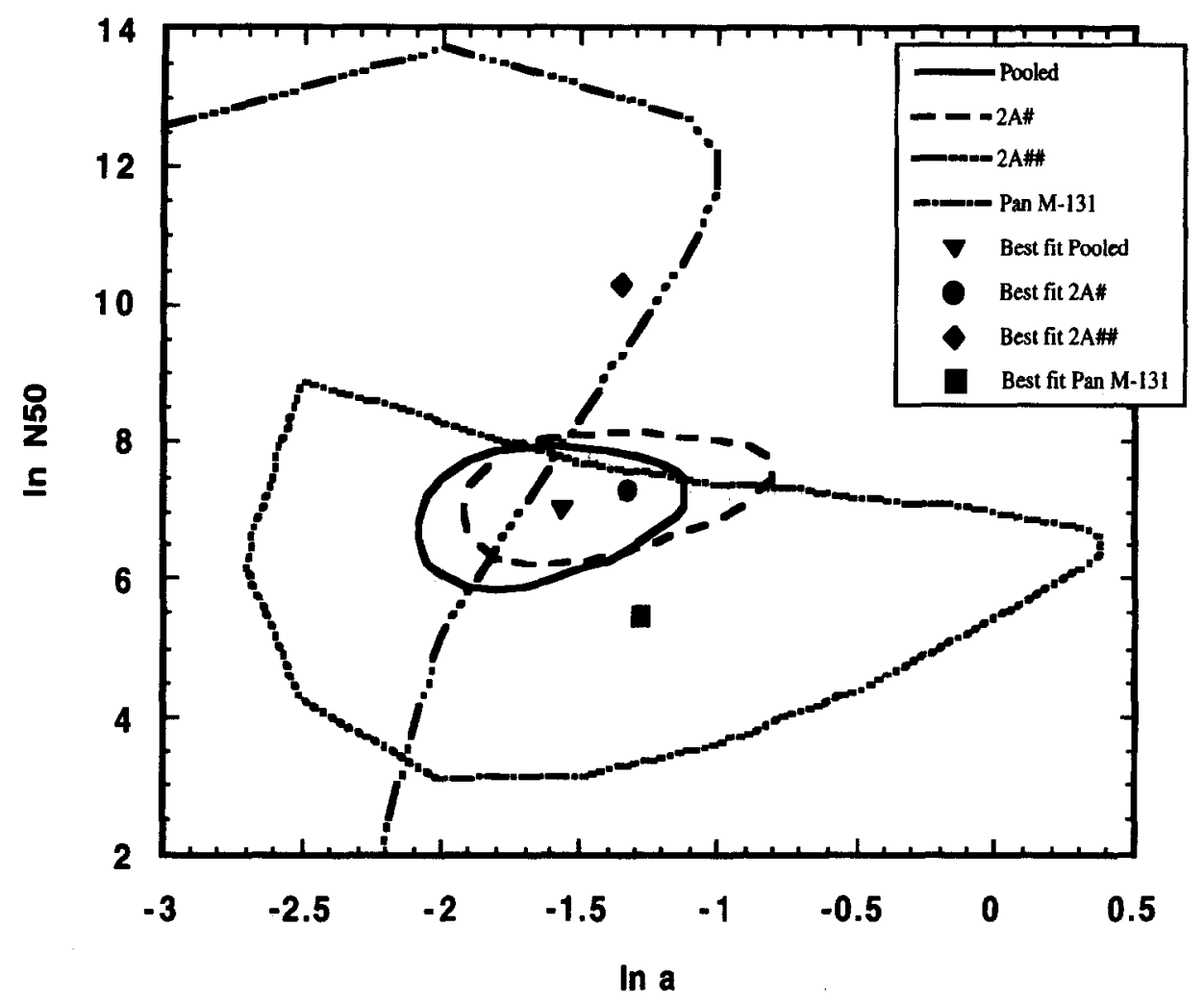

Fig. 3. $95 \%$ Confidence regions for Shigella species.

\section{Discussion}

Based on an estimated 300000 annual cases in the U.S. for Shigella and a range of $30 \%$ to $40 \%$ due to foodborne and waterborne infections and assuming that the entire U.S. population of 250 million people is at risk uniformly throughout an entire year, this would create an average individual daily risk ranging from $9.9 \times$

Table 5

Ranges of median infective dose for $95 \%$ confidence regions

\begin{tabular}{lllll}
\hline Species/strain & S. dys. 131 & S. fexneri 2A \# \# & S. flexneri 2A \# & Pooled \\
\hline Highest N50 & 6855 & 919881 & 3353 & 2721 \\
Lowest N50 & 23 & Open ended & 501 & 344 \\
Best fit N50 & 238 & 35400 & 1482 & 1120 \\
Highest $\alpha$ & 1.45 & 0.364 & 0.452 & 0.327 \\
Lowest $\alpha$ & 0.067 & Open ended & 0.146 & 0.125 \\
Best fit $\alpha$ & 0.277 & 0.144 & 0.265 & 0.209 \\
\hline
\end{tabular}




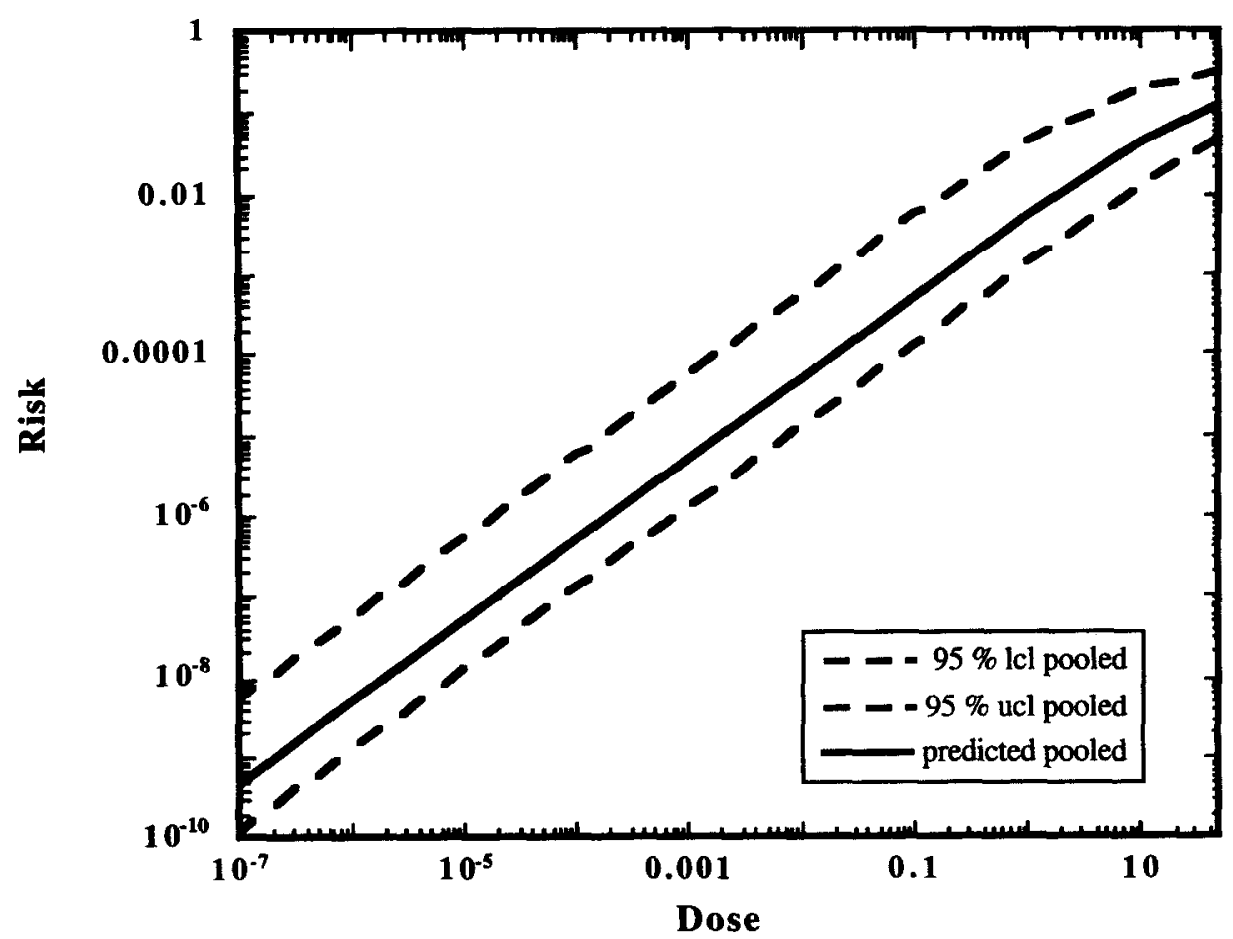

Fig. 4. Extrapolation of the dose-response relationship for Shigella species combined at low risk levels.

$10^{-7}$ to $1.3 \times 10^{-6}$. Using the dose-response relationship from the pooled Shigella model shown in Fig. 4, the average daily exposure would be $2 \times 10^{-4}$ and $3 \times$ $10^{-4}$ organisms for the minimum and maximum, with a range of $1.8 \times 10^{-5}$ to $1 \times 10^{-3}$ organisms (see Tables 6 and 7 for risk ranges and values). Since some cases of outbreaks in literature have occurred at annual local events such as picnics, swimming, and concerts, or at a vacation spot or a cruise (Rosenberg et al., 1976; Black et al., 1978; Makintubee et al., 1987; Spitka et al., 1987; Sorvillo et al., 1988; Reeve et al., 1989; Blostein, 1991; Lee et al., 1991; Lew et al., 1991), it is plausible to assume that exposure may occur only sporadically, e.g. for 7 days out of the year, with the risk on the other days being zero. The daily risk then determined over this seven day period is between $5.1 \times 10^{-5}$ to $6.9 \times 10^{-5}$ for the $30 \%$ to

Table 6

Average individual daily risk range

\begin{tabular}{lll}
\hline Exposure period & Average daily individual risk & Odds \\
\hline 1 Year & $9.9 \mathrm{E}-07-1.3 \mathrm{E}-06$ & 1 in 770000 to 1000000 \\
7 Days & $5.1 \mathrm{E}-05-6.9 \mathrm{E}-05$ & 1 in 14500 to 19600 \\
1 Day & $3.6 \mathrm{E}-04-4.8 \mathrm{E}-04$ & 1 in 2000 to 2800 \\
\hline
\end{tabular}


Table 7

Average daily dose ranges using the pooled and separate models

\begin{tabular}{llll}
\hline Exposure Period & $\begin{array}{l}\text { Average daily } \\
\text { exposure } \\
\text { (pooled } \\
\text { model) }\end{array}$ & $\begin{array}{l}95 \% \text { Confidence limits } \\
\text { (pooled model) }\end{array}$ & $\begin{array}{l}95 \% \text { Confidence limits } \\
\text { (highest and lowest model) }\end{array}$ \\
\hline 1 Year & $0.0002-0.0003$ & $1.8 \mathrm{E}-05-0.001$ & $4.6 \mathrm{E}-07-0.2$ \\
7 Days & $0.01-0.014$ & $0.001-0.05$ & $8.1 \mathrm{E}-06-11.5$ \\
1 Day & $0.07-0.1$ & $0.006-0.4$ & $5.7 \mathrm{E}-05-80.9$ \\
\hline
\end{tabular}

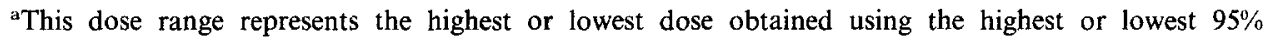
confidence limit that any separate data set provided.

$40 \%$ range of estimated cases. Using the pooled Shigella model in Fig. 4, this would correspond to an average exposure of 0.01 to 0.014 organisms, with a range of 0.001 to 0.05 organisms. Looking at Fig. 5 again, using the highest upper confidence limit and lowest lower confidence limit mentioned earlier, the average

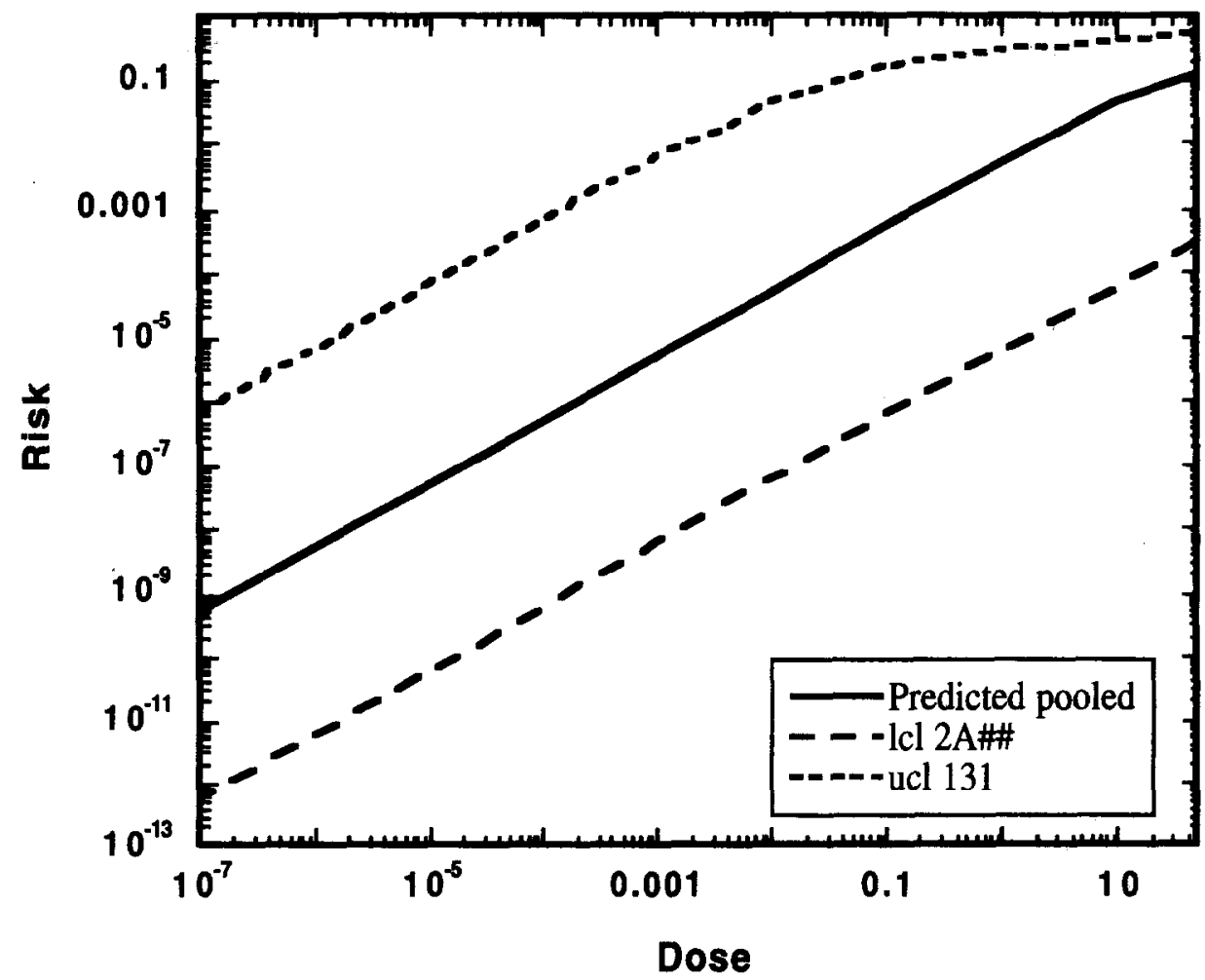

Fig. 5. Extrapolation of the dose-response relationship for Shigella species at low risk levels. Highest $95 \%$ u.c.l and lowest 1.c.l. for the Shigella species. 
Table 8

Application of pooled dose-response model to cruise ship outbreaks

\begin{tabular}{lll}
\hline Cruise ship & Viking Serenade $^{\mathrm{b}}$ & American Adventure $^{\mathrm{a}}$ \\
\hline Cruise dates & $8 / 29 / 94-9 / 1 / 94$ & $12 / 26 / 93-1 / 2 / 94$ \\
$\%$ ill & $37 \%, 1$ death & $14.8-32.3 \%$ \\
Exposure period & 1 Day & 2 Days \\
mode & food & water \\
Predicted dose & 344 Organisms/meal & $10.5-12$ Organisms $/$ glass \\
Plausible? & Yes & Yes \\
\hline
\end{tabular}

aSource: Centers for Disease Control (Centers for Disease Control and Prevention, 1994).

bSource: Sonya Anderson, Vessel Sanitation Division, CDC (Anderson, Pers. Commun.).

exposure ranges between $8 \times 10^{-6}$ to 11.5 organisms. If the assumption of a nonconstant exposure is pursued further, and it is assumed that the risk occurs only once a year ranging from $3.6 \times 10^{-4}$ to $4.8 \times 10^{-4}$, then our pooled shigella model in Fig. 4 gives us an average exposure between 0.07 to 0.1 organisms, with a range of 0.006 to 0.4 organisms. When the highest upper confidence limit and lowest lower confidence limit is used in Fig. 5, the average exposure ranges between $5.7 \times 10^{-5}$ to 81 organisms. These results for the pooled Shigella model are consistent with prior statements that it only takes ingestion of l Shigella cell to cause infection (Dupont and Hornick, 1973).

Since Shigella sonnei and Shigella flexneri are considered as the two main species of Shigella responsible for outbreaks (Dupont et al., 1969), the assumption that Shigella flexneri or a combination of Shigella flexneri and dysentariae is as or more infective may not be true. However, the data presented here shows an overlap in the Shigella dysentariae and Shigella flexneri confidence regions and limits as well as the acceptable fit of the pooled data set. This suggests that more than one species of Shigella can be pooled to give an accurate prediction for Shigella in general. As more dose-response data becomes available for different Shigella species, the validity of this suggestion will be determined.

The plausibility of the dose-response models can also be examined by evaluating the estimated doses required to cause reported outbreaks. The outbreaks chosen for evaluation are from cruise ships, because the population exposed, duration of exposure, the attack rate, and the mode of transmission was known and believed to be fairly accurate. Table 8 shows the details of two rccent cruise ship outbreaks for suspected foodborne and waterborne modes of transmission (Anderson, 1994; US Centers for Disease Control and Prevention, Pers. Commun.). When the attack rates were recalculated to represent the response for one day of the exposure period and input into the pooled dose response model, the dose required for infection can then be determined. In the case of the waterborne outbreak, a background level of risk was reported and the number of glasses resulting in the observed attack rates fit the exponential model. The upper and lower doses from the pooled model for one day responses were then divided by the corresponding number of glasses determined by the exponential model. The result was an upper and lower estimate 
of the required dose per glass of water ingested to cause the outbreak. In the case of the foodborne outbreak, one meal was the suspected mode of transmission, so no readjustment for multiple exposure or background levels were used.

As shown in Table 8 the dose estimated per meal or glass of water by the pooled model was definitely plausible considering the suspected infectivity of Shigella and lends to the credibility of the pooled model. It should be noted however, that our calculations did not take into account possible person to person transmission during the period after initial exposure due to lack of information.

\section{Conclusion}

The beta-Poisson model can be used to describe the risk associated with exposure to pathogenic Shigella. The beta-Poisson model consistently fit each of the data sets studied. The data presented shows an overlap in the Shigella dysentariae and Shigella flexneri confidence regions and limits as well as the acceptable fit of the pooled data set, which suggest that this pooled model can be used to describe Shigella in general. When the pooled Shigella model is statistically tested for difference from the separate species models, it is found to be statistically indistinguishable $\left(P_{\mathrm{o}} \geq 0.05\right)$, suggesting adequacy of the pooled Shigella model to represent the separate Shigella species for risk and exposure predictions. The pooled Shigella model shows that the average exposures based on the estimated U.S. caseload of pathogenic Shigella are lower than the estimated range of 10-100 Shigella cells previously believed to cause infection (Dupont and Hornick, 1973). The average exposure range based on U.S. caseload risk using the pooled Shigella data set and a beta-Poisson distribution was 0.01 to 0.014 organisms (confidence limits $0.001-0.05$ ) for a 7-day per annum period of exposure and ranges from 0.07 to 0.1 organisms (confidence limits $0.006-0.4$ ) for a 1-day per annum period of exposure. Application of the pooled model to two recent cruise ship outbreaks also gave reasonable estimates of the doses required to cause infection, lending to the credibility of the model.

\section{Acknowledgements}

This work has been partially supported by funding from the American Water Works Association Research Foundation.

\section{References}

Bennett, J.V., Holmberg, S.D., Rogers, M.F. and Solomon, S.L. (1987) Infectious and parasitic diseases. Am. J. Prev. Med. 3, 102-114.

Black, R.E., Craun, G.F. and Blake, P.A. (1978) Epidemiology of common-source outbreaks of shigellosis in the United States, 1961-1975. Am. J. Epidemiol. 108, 47-52. 
Blostein, J. (1991) Shigellosis from swimming in a park pond in Michigan. Public Health Rep. 106, $317-21$.

Centers for Disease Control and Prevention. 1994. EPI-AID trip report: outbreak of gastroenteritis due to Shigella flexneri on the MS Adventure. EPI-AID 94-20.

Dupont, H.L. and Hornick, R.B. (1973) Clinical approach to infectious diarrheas. Medicine 52, $265-270$.

Dupont, H.L., Hornick, R.B., Dawkins, A.T., Snyder, M.J. and Formal, S.B. (1969) The response of man to virulent Shigella flexneri. IIa. J. Infect. Dis. 119, 296-299.

Dupont, H.L., Hornick, R.B., Snyder, M.J., Libonati, J.P., Formal, S.B. and Gangarosa, E.J. (1972) Immunity in shigellosis. Il. Protection induced by oral live vaccine or primary infection. J. Infect. Dis. $125,12-16$.

Ewald, P.W. (1991) Waterborne transmission and the evolution of virulence among gastrointestinal bacteria. Epidemiol. Infect. 106, 83-119.

Furumoto, W.A. and Mickey, R. (1967a) A mathematical model for the infectivity-dilution curve of tobacco mosaic virus: Exp. Tests Virol. 32, 224.

Furumoto, W.A. and Mickey, R. (1967b) A mathematical model for the infectivity-dilution curve of tobacco mosaic virus: theoretical considerations. Virology 32, 216.

Haas, C.N. (1983) Estimation of risk due to low doses of microorganisms: a comparison of alternative methodologies. Am. J. Epidemiol. 118, 573-582.

Haas, C.N., Rose, J.B., Gerba, C. and Regli, S. (1993) Risk assessment of virus in drinking water. Risk Anal. $13,545-552$.

Lee, L.A., Ostroff, S.M., McGee, H.B., Johnson, D.R., Downes, F.P., Cameron, D.N., Bean, N.H. and Griffin, P.M. (1991) An outbreak of shigellosis at an outdoor music festival. Am. J. Epidemiol. 133, $608-15$.

Lee, Y.J. (1988) Trend in Proportions, Test For. In: S. Kotz and N. Johnson (editors), Encyclopedia of Statistical Sciences. Wiley, New York, pp. 328-334.

Levine, M.M., Dupont, H.L., Formal, S.B., Hornick, R.B., Takeuchi, A., Gangarosa, E.J., Snyder, M.J. and Libonati, J.P. (1973) Pathogenesis of Shigella dysenteriae 1 (Shiga) Dysentery. J. Infect. Dis. 127, 261-269.

Lew, J.F., Swerdlow, D.L., Dance, M.E., Griffin, P.M., Bopp, C.A., Gillenwater, M.J., Mercatente, T.M. and Glass., R.I. (1991) An outbreak of shigellosis aboard a cruise ship caused by a multiple-antibiotic-resistant strain of Shigella flexneri. Am. J. Epidemiol. 134, 413-420.

Makintubee, S., Mallonee, J. and Istre, G.R. (1987) Shigellosis outbreak associated with swimming. Am. J. Public Health 77, 166-168.

Reeve, G.D.L., Martin, J., Pappas, R.E., Thompson and Greene, K.D. (1989) An outbreak of shigellosis associated with the consumption of raw oysters. N. Engl. J. Med. 321, 224-227.

Regli, S., Rose, J.B., Haas, C.N. and Gerba, C. (1991) Modeling risk for pathogens in drinking water. J. Am. Water Works Assoc. 83, 76-84.

Rosenberg, M.L., Hazlet, K.K., Schaefer, J., Wells, J.G. and Pruneda, R.C. (1976) Shigellosis from swimming. J. Am. Med. Assoc. 236, 1849-1852.

Sorvillo, F.J., Waterman, S.H., Vogt, J.K. and England, B. (1988) Shigellosis associated with recreational water contact in Los Angeles County. Am. J. Trop. Med. Hyg. 38, 613-617.

Spitka, J.S., Dabis, F., Hargrett-Bean, N., Salcedo, J., Veillard, S. and Blake, P.A. (1987) Shigellosis at a Caribbean resort: hamburger and North American origin as risk factors. Am. J. Epidemiol. 126, $1173-1180$. 